\title{
Effect of educational program based on theory of planned behavior on promoting nutritional behaviors preventing Anemia in a sample of Iranian pregnant women
}

Ali Khani Jeihooni ${ }^{1}$, Tayebeh Rakhshani ${ }^{1}$, Pooyan Afzali Harsini ${ }^{2}$ and Mehdi Layeghias $\left.\right|^{3^{*}}$

\begin{abstract}
Background: Iron deficiency anemia (IDA) is one of the most common problems during pregnancy. The aim of this research was to determine the effect of educational program based on Theory of Planned Behavior (TPB) on promoting nutritional behaviors preventing anemia in a pregnant woman in Shiraz city, Iran.

Methods: This quasi-experimental study was done on 150 pregnant women 75 experimental and 75 control groups) who were selected using randomly sampling method in in Shiraz city, Iran, in 2020-2021. The educational intervention for the experimental group included six educational sessions for 50 or 55 min-based TPB model. A questionnaire consisted of items about demographic information, TPB constructs (attitude, perceived behavioral control, subjective norms and behavioral intention) was used to measure the nutritional behaviours preventing iron deficiency anemia in pregnancy women before and 3 months after the intervention.

Results: The results showed that before the educational intervention, there was no significant difference between the two groups in terms of knowledge, attitude, perceived behavioral control, subjective norms, behavioral intention and nutritional performance; however, three months after the educational intervention, the experimental group showed a significant increase in each of the mentioned variables. For example the mean and standard deviation score of behavioral intention after intervention in the experimental group was significantly increased (25.57 \pm 1.66 , $P=0.001)$,and the mean and standard deviation score of performance after intervention in the experimental group was significantly increased $(31.03 \pm 2.19, P=0.001),(P<0.05)$.
\end{abstract}

Conclusions: After the educational intervention, the experimental group showed a significant increase in of the knowledge, attitude, perceived behavioral control, subjective norms, behavioral intention and nutritional performance. Therefore the results of the study showed positive effect of nutrition educational intervention program base on TPB model on improvement of iron deficiency anemia preventive behaviours in the pregnancy women.

Keywords: Iron-deficiency Anemia, Students, Nutrition, Education, TPB

*Correspondence: public.health1919@gmail.com

${ }^{3}$ Department of Health Promotion, School of Health, Shiraz University

of Medical Sciences, Shiraz, Iran

Full list of author information is available at the end of the article

\section{Background}

Anemia is a clinical disorder characterized by a decrease in hemoglobin concentration. Generally more than two billion people in the world, including more than half of pregnant women suffer from anemia [1, 2]. The prevalence of anemia among pregnant women in developing 
countries is about 40-60\% [2]. The World Health Organization (WHO) also estimates the prevalence of anemia in pregnant women in the Eastern Mediterranean at 44.2\%. In this report, the prevalence of anemia in Iranian pregnant women was more than $40 \%$ [3]. When the prevalence of anemia in a population reaches more than $40 \%$, it becomes a serious health concern [4]. Therefore, iron deficiency anemia (IDA) is one of the most common problems during pregnancy $[4,5]$.

Iron-deficiency anemia (IDA) can cause serious harm to the mother and fetus [6]. Since pregnancy is considered as one of the most important periods in a woman's life [7], iron deficiency anemia (IDA) has dangerous effects on mother and fetus and reduces fertility, preterm delivery, severe neonatal birth weight, increased spontaneous abortion, increased fetal mortality and postpartum hemorrhage $[8,9]$. In addition, the consequences of anemia in pregnant women affect the social and economic development of individuals [10]. Anemia can be caused by iron deficiency, impaired absorption, iron loss, or increased need for iron [11].

Despite the fact that free iron supplementation has been an important part of prenatal care in primary health care centers in Iran since 1983, anemia during pregnancy is still a major nutritional problem [2]. Preventive measures aimed at controlling anemia among pregnant women are very important in terms of public health benefits and cost-effectiveness due to the reduction of mortality and prevention of its complications among mothers and infants [12]. One of the most effective ways to reduce these adverse outcomes during pregnancy is to engage in self-care behaviors [13].

The vulnerability of pregnant women and the complications of anemia make it necessary to anticipate effective and appropriate measures and programs in this regard. Recognizing behavior and the factors influencing it to change or modify existing behaviors and replace new behaviors for the effectiveness of these programs is one of the effective strategies that emphasizes the role of health education and health promotion models $[8,12]$.

Therefore, health education and health promotion models are good guides for analyzing the factors affecting behavior, planning, and effective intervention, and they are recommended to obtain useful and effective results [14].. The most important step in recognizing the various factors affecting behavior, in designing and implementing educational and intervention programs, is to choose the appropriate model or theory. One of the effective theories in the successful conversion of adverse behavior to healthy behavior is the theory of planned behavior (TPB) $[15,16]$. This theory considers individual beliefs, social factors and motivation to follow important people in life as a network of factors influencing behavior change.
As a theory of behavior change (cognitive-social model of value expectation), it states that intention is the main determinant of behavior and is influenced by the following three independent constructs:

1. An individual's attitude toward behavior that is shaped by behavioral beliefs and evaluation of behavioral outcome.

2. The Subjective norms of this construct is shaped by normative beliefs and motivation to follow.

3. Perceived behavioral control which this construct is influenced by control belief and perceived power [15, 16].

Of course, numerous successful studies have been conducted worldwide to improve nutritional behaviors associated with iron deficiency anemia using ТРВ $[8,12,17]$. Therefore, considering that anemia is one of the causes of maternal mortality during pregnancy and that maternal mortality is considered as one of the important indicators of the quality of health services in a country [18] And due to nutritional problems during pregnancy, including the high prevalence of anemia in Iranian pregnant women [3] and it becomes a serious concern for their health [4]. the present study was conducted to determine the effectiveness of the TPB in promoting nutritional behaviors preventing anemia in a sample of Iranian pregnant women. Our hypothesis was that after the intervention based on "TPB", the mean scores of nutritional behaviors preventing anemia in pregnant women were statistically significant in the experimental and control groups.

\section{Methods}

Study design and sample size This quasi-experimental study was conducted on 150 pregnant women under the auspices of health centers of Shiraz in 2020-2021. For sampling, from among urban health centers of Shiraz, two centers were randomly selected (one center for the experimental group and one center for the control group). The sampling method in each health center was simple random. In this way, first a list of all pregnant mothers in each health center was prepared and then the participants were randomly selected using a random number table. The samples were then invited to attend a health center on a certain day to get acquainted with. They were also explained the study objectives, and informed consent was obtained from participants. The sample size was calculated based on Jahangiri et al. [12]. Using the formula for comparing the mean of the variables, 40 people were determined for each group. To increase the accuracy and power of the study, 75 people per group were considered. Inclusion criteria were 
willingness to participate and literate pregnant women at the beginning of the fourth month of pregnancy who were referred to health centers and filed a case of an underlying disease related to anemia, such as a history of inherited and acquired diseases, including thalassemia with no history of bleeding. The exclusion criteria were unwillingness to participate in the study, absence from more than two training sessions and questionnaire completion sessions, relocation of the pregnant mother and the impossibility of accessing her.

Instruments The data collection tool included a questionnaire that was used in the study of Jahangiri et al., whose validity and reliability were confirmed [12]. Cronbach's alpha for knowledge, attitude, subjective norm, perceived behavioral control, behavioral intention, and performance checklist was $0.71,0.80,0.79,0.76$, and 0.79 , respectively. The total reliability of the tool was also 0.80 .

The questionnaire included demographic information (age, mother's education, spouse's education, occupation, gestational week, number of children, family income, and hemoglobin level) and 10 questions on knowledge. A TPB-based questionnaire includes: 12 questions on attitude (For example: like any other woman, I am at risk for complications from iron deficiency in pregnancy. I do not need to take iron pills because my nutrition is good.), measured using a five-point Likert scale from (1: I strongly agree) to (5: I strongly disagree), higher scores indicate a more positive attitude toward the corresponding health behavior. 5 questions on perceived behavioral control (For example: Even if the iron pill makes me nauseous, I still take it. Due to the high cost of meat, I can use legumes and eggs as a suitable alternative.), measured by a five-point Likert scale from (1: I strongly agree) to (5: I strongly disagree). Higher scores indicate higher levels of perceived control to engage in the corresponding health behavior. 6 questions on subjective norms (For example: My husband encourages me to eat right and take iron pills. I am encouraged by health professionals when I have the right diet and take supplements.), measured by a five-point Likert scale from (1: I strongly disagree) to (5: I strongly agree). Higher scores indicate greater perceived pressure to engage in the behavior. 6 questions on behavioral intention (For example: I plan to include ironrich foods in my diet, such as meat and legumes. I plan to take iron pills regularly until the end of my pregnancy.), using afive-point Likert scale ranging (strongly disagree) to (strongly agree). Higher scores indicate stronger intentions to engage in the corresponding health behavior. The possible score was between -10 to +10 for each specific factor. and 9 questions on performance checklist.
After the selection of the experimental and control group, the purpose of the study and how to do the work were explained to the participants and the staff of the health centers. The questionnaire was completed by two experimental and control groups.

Educational intervention Based on the pre-test results, the educational content was prepared based on the TPB. The educational intervention for the experimental group consisted of 6 sessions of 50-55 min through lectures, questions and answers, group discussion, educational posters and pamphlets, videoclips and powerpoint. The training program was conducted by a doctor of health education and health promotion, a nutritionist and a gynecologist in collaboration with two experts from the women's health unit of Shiraz health center. Training sessions were held for 3 groups of 25 (one session per week). These sessions were about anemia in pregnancy, infection and complications of the disease, ways to prevent infection, prevalence of anemia among pregnant women, correct or change misconceptions and strengthen true beliefs, the implementation of nutritional behaviors to prevent anemia in pregnancy and its positive effects on maternal and fetal health. Each woman was also asked to describe her previous experiences with nutrition and the behaviors they should replace. Key barriers were discussed by pregnant women themselves, and solutions were offered to overcome those barriers. The benefits of having a preventive diet and regular use of supplements and solutions to reduce gastrointestinal side effects caused by their consumption were presented to pregnant women. The nutritionist was asked to speak for $20 \mathrm{~min}$ about the need for anemia-preventing nutritional behaviors for pregnant women, followed by a group discussion. One of the meetings was held with the presence of spouses and officials of health centers, and they received information about nutritional behaviors preventing anemia, emphasizing their supportive role.

At the end of the sessions, women and their spouses received educational $\mathrm{CDs}$ and booklets. Women were divided into groups of 8-10 and groups of friends were formed. In order to maintain and promote the activity of the experimental group, they received an educational text message per week. One month and two months after the educational intervention, two virtual follow-up sessions were held for women. But the control group only received routine training at the time of referral and only face-to-face from health care providers. (The intervention plan be stated in the Table 1). Three months after the educational intervention, both experimental and control groups completed the questionnaire. The control group, at the end of the study, received an educational booklet. 


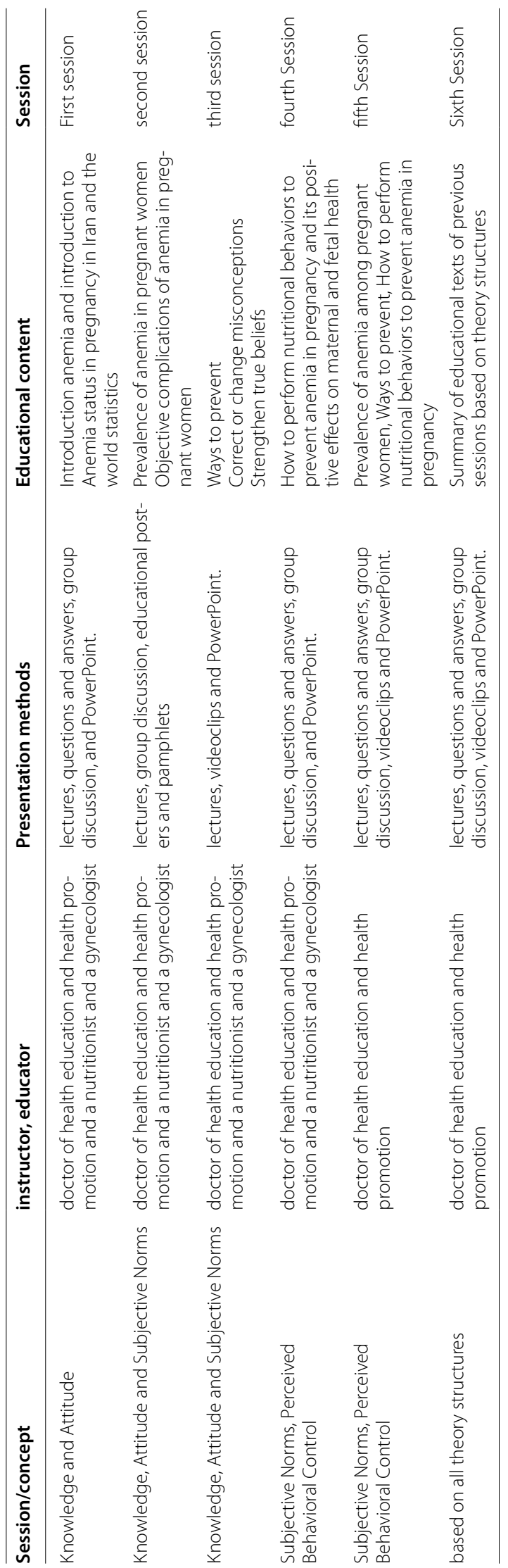


Five women in the experimental group and three women in the control group did not complete the post-test questionnaire; therefore, the final analysis was performed on 70 people in the experimental group and 72 people in the control group. For ethical considerations, while obtaining permission from the ethics committee of Shiraz University of Medical Sciences with the code (IR.SUMS. REC.1400.222), a written consent was obtained from participants and the goals, importance and necessity of the study was explained to them. Participants were also assured that their information would remain confidential.

Analysis data Data were analysed using SPSS 22. We conducted descriptive and inferential analyses, including frequencies (for categorical variables) and mean (for continuous variables), for all demographic data and questionnaire scores.using Chi-square, independent t-test and paired t-test and the significance level was considered 0.05 .

\section{Results}

142 pregnant women (70 in the experimental group and 72 in the control group) participated in this study. The mean and standard deviation of age in the experimental group was $(31.53 \pm 6.22)$ years and of control group was $(30.49 \pm 5.85)$ years. The mean and standard deviation of level of hemoglobin in the experimental group was $(12.77 \pm 1.10)$ and of control group was (13.09 \pm 1.07$)$. The sample housewife in the experimental group was $(N=60)$, The sample housewife in the control group was $(N=59)$, The sample employed in the experimental group was $(N=10)$, The sample employed in the control group was $(N=13)$.

Based on the independent t-test, the differences between the two groups were not significant in terms of quantitative demographic variables (age, gestational age with previous pregnancy, number of children, gestational week, hemoglobin level) $(P<0.05)$. (Table 2$)$.

Based on the chi-square test results, in terms of qualitative demographic variables (occupation, education, spouse's education and occupation, and monthly income), the two groups were the same (Table 3).

The results showed that there was no significant difference between the two groups in terms of knowledge, attitude, perceived behavioral control, subjective norms, behavioral intention, and nutritional performance before the educational intervention. However, three months after the educational intervention, the experimental group showed a significant increase in each of the mentioned variables.

According to the paired t-test, the mean and standard deviation score of knowledge after intervention
Table 2 Comparison of experimental and control groups in terms of quantitative demographic variables

\begin{tabular}{|c|c|c|c|c|c|}
\hline \multirow[t]{2}{*}{ Variable } & \multicolumn{2}{|c|}{$\begin{array}{l}\text { Experimental } \\
\text { group }\end{array}$} & \multicolumn{2}{|c|}{ Control group } & \multirow[t]{2}{*}{$P$-value } \\
\hline & $M$ & SD & $M$ & SD & \\
\hline Age & 31.53 & 6.22 & 30.49 & 5.85 & 0.352 \\
\hline $\begin{array}{l}\text { Interval between previ- } \\
\text { ous pregnancy }\end{array}$ & 3.62 & 3.28 & 3.56 & 3.18 & 0.612 \\
\hline Number of children & 1.22 & 0.65 & 1.08 & 0.61 & 0.655 \\
\hline Gestational week & 17.05 & 1.28 & 16.60 & 1.27 & 0.304 \\
\hline $\begin{array}{l}\text { Level of hemoglobin } \\
\text { independent t-test }\end{array}$ & 12.77 & 1.10 & 13.09 & 1.07 & 0.376 \\
\hline
\end{tabular}

in the experimental group was significantly increased $(8.19 \pm 1.05, P=0.001)$, while the mean and standard deviation score of knowledge after intervention in the control group was not significant $(4.39 \pm 1.14, P=0.262)$. In addition, after the intervention, the mean and standard deviation score of attitude after intervention in the experimental group was significantly increased (50.24 \pm 4.28 , $P=0.001)$, the mean and standard deviation score of subjective Norms after intervention in the experimental group was significantly increased (23.10 \pm 1.70 , $P=0.001$ ), the mean and standard deviation score of perceived behavioral control after intervention in the experimental group was significantly increased $(20.88 \pm 1.64$, $P=0.001)$, the mean and standard deviation score of behavioral intention after intervention in the experimental group was significantly increased $(25.57 \pm 1.66$, $\mathrm{P}=0.001$ ), and the mean and standard deviation score of performance after intervention in the experimental group was significantly increased $(31.03 \pm 2.19, \mathrm{P}=0.001)$, but these factors did not change significantly after intervention in the control group (Table 4).

\section{Discussion}

The present study aimed to investigate the effect of educational intervention based on the TPB on promoting nutritional behaviors preventing anemia in a sample of Iranian pregnant women. There are several risks to mothers during pregnancy. Anemia is one of the most common blood disorders and risks during pregnancy that may affect the health of mother and fetus; therefore, identifying the factors affecting the improvement of nutritional behaviors preventing anemia in pregnant women is of great importance.

In the present study, the mean score of knowledge, attitude, subjective norms, perceived behavioral control, behavioral intention and nutritional performance in both experimental and control groups before the intervention were not statistically significant. This is consistent with 
Table 3 Comparison of experimental and control groups in terms of qualitative demographic variables

\begin{tabular}{|c|c|c|c|c|c|c|}
\hline \multirow[t]{2}{*}{ Variable } & & \multicolumn{2}{|c|}{ Experimental group } & \multicolumn{2}{|c|}{ Control group } & \multirow[t]{2}{*}{ p-value } \\
\hline & & $\mathbf{N}$ & $\mathbf{P}$ & $\mathbf{N}$ & $\mathbf{P}$ & \\
\hline \multirow[t]{2}{*}{ Occupation } & Housewife & 60 & 85.71 & 59 & 81.94 & 0.464 \\
\hline & Employed & 10 & 14.29 & 13 & 18.06 & \\
\hline \multirow[t]{3}{*}{ Household monthly income } & $<30$ million Rials & 36 & 37.14 & 22 & 30.56 & 0.180 \\
\hline & 30-60 million Rials & 32 & 45.72 & 30 & 41.66 & \\
\hline & $>60$ million Rials & 12 & 17.14 & 20 & 27.78 & \\
\hline \multirow[t]{4}{*}{ Education } & Primary school & 5 & 7.14 & 7 & 9.72 & 0.279 \\
\hline & Secondary school & 16 & 22.86 & 21 & 29.17 & \\
\hline & High school & 34 & 48.57 & 28 & 38.89 & \\
\hline & College & 15 & 21.43 & 16 & 22.22 & \\
\hline \multirow[t]{5}{*}{ Spouse's education } & Illiterate & 4 & 5.71 & 6 & 8.33 & 0.264 \\
\hline & Primary school & 6 & 8.57 & 8 & 11.11 & \\
\hline & Secondary school & 15 & 21.43 & 18 & 25 & \\
\hline & High school & 29 & 41.43 & 21 & 29.17 & \\
\hline & College & 16 & 22.86 & 19 & 26.39 & \\
\hline \multirow[t]{2}{*}{ Spouse's occupation } & Employed & 38 & 54.29 & 35 & 48.61 & 0.432 \\
\hline & Unemployed & 32 & 45.71 & 37 & 51.39 & \\
\hline
\end{tabular}

Table 4 Comparison of mean scores of knowledge, attitude, perceived behavioral control, subjective norms, behavioral intention and nutritional performance of pregnant women in experimental and control groups before and three months after educational intervention

\begin{tabular}{|c|c|c|c|c|}
\hline Variable & group & $\begin{array}{l}\text { Before intervention } \\
M \pm S D\end{array}$ & $\begin{array}{l}\text { After intervention } \\
M \pm S D\end{array}$ & P-value \\
\hline \multirow[t]{3}{*}{ Knowledge } & Experimental & $4.14 \pm 1.25$ & $8.19 \pm 1.05$ & 0.001 \\
\hline & Control & $4.25 \pm 1.08$ & $4.39 \pm 1.14$ & 0.262 \\
\hline & The significance level & 0.258 & 0.001 & \\
\hline \multirow[t]{3}{*}{ Attitude } & Experimental & $26.14 \pm 4.55$ & $50.24 \pm 4.28$ & 0.001 \\
\hline & Control & $28.50 \pm 4.16$ & $29.18 \pm 4.22$ & 0.233 \\
\hline & The significance level & 0.239 & 0.001 & \\
\hline \multirow[t]{3}{*}{ Perceived behavioral control } & Experimental & $10.26 \pm 1.73$ & $20.88 \pm 1.64$ & 0.001 \\
\hline & Control & $10.15 \pm 1.66$ & $11.02 \pm 1.68$ & 0.237 \\
\hline & The significance level & 0.287 & 0.001 & \\
\hline \multirow[t]{3}{*}{ Subjective Norms } & Experimental & $13.18 \pm 1.92$ & $23.10 \pm 1.70$ & 0.001 \\
\hline & Control & $12.58 \pm 1.89$ & $13.35 \pm 1.78$ & 0.253 \\
\hline & The significance level & 0.241 & 0.001 & \\
\hline \multirow[t]{3}{*}{ Behavioral intention } & Experimental & $15.86 \pm 1.40$ & $25.57 \pm 1.66$ & 0.001 \\
\hline & Control & $14.17 \pm 1.62$ & $16.02 \pm 1.58$ & 0.214 \\
\hline & The significance level & 0.224 & 0.001 & \\
\hline \multirow[t]{3}{*}{ Performance } & Experimental & $17.05 \pm 2.21$ & $31.03 \pm 2.19$ & 0.001 \\
\hline & Control & $18.06 \pm 2.27$ & $19.26 \pm 2.34$ & 0.251 \\
\hline & The significance level & 0.245 & 0.001 & \\
\hline paired t-test & & & & \\
\hline
\end{tabular}


the results of some other studies $[8,17,19,20]$. Perhaps the low mean score of these constructs before the educational intervention is due to the lack of codified and model-oriented training programs using participatory programs and combined educational methods [21].

However, three months after the intervention program, the mean score of knowledge, attitude, subjective norms, perceived behavioral control, behavioral intention and nutritional performance in the experimental group were statistically significant with that of the control group. This was consistent with the results of other studies, indicating the effectiveness of TPB-based educational intervention [8, 22]. Studies by Kamalifard, M. et al. [21], Anderson, A. S. et al. [23] concluded that the training package in their study could improve the nutritional knowledge, attitudes and behaviors of pregnant mothers.

The mean score of knowledge in the present study in the experimental group increased significantly after the intervention. This, consistent with other studies, showed that to improve nutritional behaviors during pregnancy, increasing mothers' knowledge is a necessary and effective $[24,25]$. Of course, the willingness of the participants to participate in the training programs is very important; for example, the results of a study by Jarrah S. S. et al. showed that most participants are very aware of the prevention of anemia and iron deficiency, but many of them wanted to know more [26].

A study by Pawlak R. et al. showed that applying this theory could lead to a positive attitude towards behavioral intention and improve nutritional behaviors [27]. In this regard, it can be concluded that in the present study, educational intervention based on the TPB could be effective in improving the attitude of pregnant mothers. Consistent with our study, the results of other studies indicated that educational programs have an effective role in creating a positive attitude toward nutritional behaviors $[8,28]$.

Subjective norms are considered as a secondary predictor of behavioral intention, and a person who believes that certain people approve of behavior and are motivated to meet their expectations has positive subjective norms. In this study, spouses and officials of health centers were considered as subjective norms. Similar studies have also considered the role of spouses and friends in subjective norms $[8,29]$. Based on Table 4 , the mean score of subjective norms in the experimental group was significantly different after the educational intervention, which is consistent with the results of some other studies $[17,19]$. However, this is not consistent with the results of studies by Ahmadi et al. [30] and Pawlak et al. [27]. This could have a variety of reasons, including cultural differences and even people who are considered important in the study. For example, in their study, Jarrah SS et al. Discuss the role of cultural conditions in transmitting important health information to others.

Perceived behavioral control refers to an individuals' understanding of how much control they have over their voluntary actions. Our intervention program in the present study could improve the perceived behavioral control in the experimental group. The results of this study were consistent with the results of the study by Alami et al. [17]. Of course, several studies have examined this issue from different aspects. Lack of financial resources, inadequate access to health care centers are among the concerns associated with reducing healthy nutritional behaviors [26, 31]. Or, for example, another study states that if pregnant women feel that environmental factors such as facilities and barriers are under their control, they will have desirable nutritional behaviors [27].

Based on the TPB, the most important determinant of behavior is behavioral intention. In this study, behavioral intention also showed a significant increase in the experimental group three months after the educational intervention. This is consistent with the results of other similar studies $[8,17,19]$.

The mean score of nutritional performance in the experimental group showed a significant increase after the educational intervention, while no significant change was observed in the control group. The results of this study showed that the training program was effective in promoting optimal nutritional behaviors and was consistent with the results of other similar studies [19, 32]. Also, Jalambadani et al. could significantly improve the nutritional behaviors associated with folic acid consumption in pregnant women after the intervention [22].

The results of this study showed that implementing intervention programs using theory and model of health education and health promotion can effectively improve the desired preventive behaviors. The results of numerous similar studies that have used the TPB support the results of the present study $[8,17,22]$.

The present study also had some limitations. Household economic status was one of the variables there search team was forced to disregard this variable because of the participants' lack of clear responses to the issue, and the lack of accurate information on their economic status in the household file.

\section{Conclusion}

Carefully choosing appropriate theories of health education and health promotion in the design and implementation of educational interventions is one of the most important factors in the effectiveness of educational interventions. Using these theories, the most important components and determinants of health behavior are identified and the components of educational programs could improve the desired 
and effective components at a higher cost, increasing the quality and effectiveness of educational programs. In this study, the TPB-based educational intervention could improve the nutritional behaviors of pregnant women; therefore, our suggestion is that the theory could be used as a suitable framework in a wider population to improve the nutritional performance associated with iron deficiency anemia in pregnant women.

\section{Abbreviations}

IDA: Iron Deficiency Anemia; TPB: Theory of Planned Behavior..

\section{Acknowledgements}

This study approved by the Shiraz University of Medical Sciences. Our warm thanks go to the Research and Technology Dept. of Shiraz University of Medical Sciences, as well as women of Shiraz city for their participation in the study.

\section{Authors' contributions}

AKHJ, TR, PAH and ML assisted in conceptualization and design of the study, oversaw data collection, conducted data analysis and drafted the manuscript. AKHJ and TR conceptualized and designed the study, assisted in data analysis and reviewed the manuscript. AKHJ, TR, PAH and ML assisted in study conceptualization and reviewed the manuscript. All authors read and approved the final manuscript.

\section{Funding}

This research was supported by the Shiraz University of Medical Sciences.

\section{Availability of data and materials}

The datasets used and/or analysed during the current study are available from the corresponding author upon reasonable request.

\section{Declarations}

\section{Ethical approval and consent to participate}

Ethical approval was obtained from the human Research Ethics committee at the Shiraz University of Medical Sciences (ethical code: IR.SUMS.REC.1400.222). All study participants provided written informed consent. Permission was also obtained to digitally record all interviews. Confidentiality and anonymity were ensured. All methods were carried out in accordance with relevant guidelines and regulations. The ethics committee approved the procedure for verbal consent since the study is observational and respected the code of ethics as stated in the declarations of helsinki.

\section{Consent for publication}

Not Applicable.

\section{Competing interests}

The authors declare that they have no competing interests.

\section{Author details}

${ }^{1}$ Nutrition Research Center, Department of Public Health, School of Health, Shiraz University of Medical Sciences, Shiraz, Iran. ${ }^{2}$ Department of Public Health, School of Health, Kermanshah University of Medical Sciences, Kermanshah, Iran. ${ }^{3}$ Department of Health Promotion, School of Health, Shiraz University of Medical Sciences, Shiraz, Iran.

\section{Received: 1 July 2021 Accepted: 23 November 2021}

Published online: 01 December 2021

\section{References}

1. Gebreamlak B, Dadi AF, Atnafu A. High adherence to iron/folic acid supplementation during pregnancy time among antenatal and postnatal care attendant mothers in governmental health centers in Akaki Kality
Sub City, Addis Ababa, Ethiopia: hierarchical negative binomial poisson regression. PLoS One. 2017;12(1):e0169415.

2. Baharzadeh K, Marashi T, Saki A, Zare Javid A, Araban M. Using of health belief model to promote preventive behaviors against iron deficiency anemia among pregnant women. J Res Health. 2017;7(2):754-62.

3. De Benoist B, Cogswell M, Egli I, McLean E. Worldwide prevalence of anaemia 1993-2005; WHO Global Database of anaemia. 2008.

4. Barooti E, Rezazadehkermani M, Sadeghirad B, Motaghipisheh S, Tayeri $S$, Arabi M, et al. Prevalence of iron deficiency anemia among Iranian pregnant women; a systematic review and meta-analysis. J Reproduct Infertility. 2010;11(1):17.

5. Gautam CS, Saha L, Sekhri K, Saha PK. Iron deficiency in pregnancy and the rationality of iron supplements prescribed during pregnancy. Medsc J Med. 2008;10(12):283.

6. Lone FW, Qureshi RN, Emanuel F. Maternal anaemia and its impact on perinatal outcome. Tropical Med Int Health. 2004;9(4):486-90.

7. Samareh S, Esmaeilzadeh A, Rahmani K, Kalantari N, Azadbakht L, KHOUSH FM. Food consumption pattern in pregnant women attending prenatal care centers in Maku. 2006.

8. Jalambadani Z, Borji A, Delkhosh M. The effect of education based on the theory of planned behavior on iron supplementation among pregnant women. Korean J Fam Med. 2018;39(6):370.

9. Gedefaw L, Ayele A, Asres Y, Mossie A. Anaemia and associated factors among pregnant women attending antenatal care clinic in Walayita Sodo town, southern Ethiopia. Ethiop J Health Sci. 2015;25(2):155-64.

10. Abdulwahid RG, Ahmed HM. Prevalence and severity of anemia among pregnant women in primary health centers/Erbil City. Kurdistan J f Appl Res. 2017;2(2):52-7.

11. Karaoglu L, Pehlivan E, Egri M, Deprem C, Gunes G, Genc MF, et al. The prevalence of nutritional anemia in pregnancy in an east Anatolian province. Turkey BMC Public Health. 2010;10(1):1-12.

12. Jahangiri Z, Shamsi M, Khorsandi M, Moradzadeh R. The assessment of the theory of planned behavior structures on nutritional prophylactic treatment of anemia in pregnant women of arak city in 2018. J Arak Univ Med Sci. 2018;21(5):42-52.

13. Izadirad H, Nohtani $V$, Aliahmadi M, Pourhaji F, Niknami S. The effect of educational intervention based on the integrated model of health belief with the structure of social support on self-care behaviors during pregnancy. Iran J Health Education Health Prom. 2021;8(4):324-35.

14. Kaveh MH, Layeghiasl M, Nazari M, Ghahremani L, Karimi M. What Are the Determinants of a Workplace Health Promotion? Application of a Social Marketing Model in Identifying Determinants of Physical Activity in the Workplace (a Qualitative Study). Frontiers in Public Health. 2020;8.

15. Glanz K, Rimer BK, Viswanath K. Health behavior. Theory, research, and practice. 2015;5.

16. Fertman $\mathrm{Cl}$, Grim M. Health promotion programs: from theory to practice: John Wiley \& Sons; 2016.

17. Alami A, Tavakoly Sany SB, Tehrani H, Lael-Monfared E, Hosseini Z, Jafari A. The effect of educational intervention on iron and vitamin D consumption based on the theory of planned behaviour in Iranian adolescent girls: a quasi-experimental study. Int J Health Promot Educ. 2019;57(6):316-31.

18. Salama AM. Utilizing health belief model to enhance the preventive behavior against iron-deficiency anemia among pregnant women. IOSR J Nursing Health Sci. 2018;7:59-69.

19. Jalambadani Z, Shojaei Zadeh D, Hoseini M, Sadeghi R. The effect of education for iron consumption based on the Theory of planned behavior in pregnant women in Mashhad. J Clin Nursing Midw. 2015;4(2).

20. Alami A, Sany SBT, Lael-Monfared E, Ferns GA, Tatari M, Hosseini Z, et al. Factors that influence dietary behavior toward iron and vitamin D consumption based on the theory of planned behavior in Iranian adolescent girls. Nutr J. 2019;18(1):1-9.

21. Kamalifard M, Mohammad-Alizade-Charandabi S, Ebrahimi-mamegani M, Asghari-Jafarabadi M, Omidi F. The effect of an educational package on nutritional knowledge, attitude, and behavior of pregnant women. Iranian J Med Education. 2012;12(9):686-97.

22. Jalambadani Z, Delavari Heravi M, Noori SM. Folic acid consumption based on the theory of planned behaviour in pregnant women. J Obstet Gynaecol. 2020;40(1):37-9.

23. Anderson AS, Campbell DM, Shepherd R. The influence of dietary advice on nutrient intake during pregnancy. Br J Nutr. 1995;73(2):163-77. 
24. Chang S, Zeng L, Brouwer ID, Kok FJ, Yan H. Effect of iron deficiency anemia in pregnancy on child mental development in rural China. Pediatrics. 2013;131(3):e755-e63.

25. Khoshnevisan K. Kalantaree, Valaee, Shaheedee. Effect of nutrition education and diet modification in iron depleted preschool children in nurseries in Tehran: a pilot study. Int J Vitam Nutr Res. 2004;74(4):264-8.

26. Jarrah SS, Halabi JO, Bond AE, Abegglen J. Iron deficiency anemia (IDA) perceptions and dietary iron intake among young women and pregnant women in Jordan. J Transcult Nurs. 2007:18(1):19-27.

27. Pawlak R, Brown D, Meyer MK, Connell C, Yadrick K, Johnson J, et al. Theory of planned behavior and multivitamin supplement use in Caucasian college females. J Prim Prev. 2008;29(1):57-71.

28. Mashoofi M, Hosseini M, Wakili Z, Mahmoodi Keli M, Shahrivar F. The effect of education on knowledge, attitude \& practice of mid-school girls on iron-deficiency anemia in Khalkhal in 2009. J Health. 2010;1 (3):57-66.

29. Kothe EJ, Mullan B, Butow P. Promoting fruit and vegetable consumption. Testing an intervention based on the theory of planned behaviour. Appetite. 2012;58(3):997-1004.

30. Ahmadi Tabatabaei S, Taghdisi M, Nakheei N, Balali F. Effect of educational intervention based on the theory of planned behaviour on the physical activities of Kerman health center's staff (2008). J Babol Univ Med Sci. 2010;12(2):62-9.

31. Alami A, Zarei F, Tehrani H, Hosseini Z, Jafari A. Perceived challenges of the schools Iron aid National Plan from stakeholder perspectives. Tehran Univ Med J TUMS Publ. 2019;77(4):257-66.

32. Hazavehei SMM, Jalili Z, Heydarnia AR, Faghihzadeh S. Application of the PRECEDE model for controlling iron-deficiency anemia among children aged 1-5, Kerman, Iran. Promot Educ. 2006;13(3):173-7.

\section{Publisher's Note}

Springer Nature remains neutral with regard to jurisdictional claims in published maps and institutional affiliations.

Ready to submit your research? Choose BMC and benefit from:

- fast, convenient online submission

- thorough peer review by experienced researchers in your field

- rapid publication on acceptance

- support for research data, including large and complex data types

- gold Open Access which fosters wider collaboration and increased citations

- maximum visibility for your research: over $100 \mathrm{M}$ website views per year

At BMC, research is always in progress.

Learn more biomedcentral.com/submissions 